\title{
\begin{tabular}{l|l} 
JURNAL EKONOMI DAN MANAJEMEN \\
\hline
\end{tabular} \\ P-ISSN: 2598-9022/ E-ISSN: 2598-9618 \\ Available at: http://e-journal.unipma.ac.id/index.php/capital
}

\section{Adopsi E-Commerce Dalam Mendukung Perkembangan Usaha Mikro Kecil Dan Menengah (UMKM) Di Masa Pandemi Covid-19}

\author{
Adriani Kala'lembang \\ Teknik Informatika, Institut Teknologi dan Bisnis Asia Malang \\ email: adriani.riny@gmail.com
}

\begin{abstract}
The Covid-19 pandemic struck Indonesia and also the rest of the world, which has a huge impact in the Micro, Small and Medium Enterprises (MSMEs). It is necessary to have a big movement to revive the economic passion in Indonesia, especially MSMEs, one of which is by utilizing e-commerce. This paper presents a conceptual framework for adopting e-commerce. Based on the results of a review of several articles, it was concluded that three factors could be used to adopt e-commerce, including, organizational characteristics, environmental characteristics, and leadership characteristics. To test the benefits and ease of using e-commerce, it can use the Technology Acceptance Model (TAM) theory.
\end{abstract}

Keywords: e-commerce, organizational characteristics, external influences, leadership, Technology Acceptance Model

\begin{abstract}
ABSTRAK
Pandemi Covid-19 sedang melanda Indonesia dan juga seluruh dunia yang memberikan dampak yang sangat besar salah satunya pada Usaha Mikro Kecil dan Menengah (UMKM). Diperlukan adanya pergerakan yang besar untuk kembali membangkitkan gairah perekonomian di Indonesia khususnya UMKM yaitu salah satunya dengan memanfaatkan e-commerce. Tulisan ini menyajikan kerangka konseptual untuk mengadopsi e-commerce. Berdasarkan hasil review beberapa artikel, disimpulkan bahwa ada tiga faktor yang dapat digunakan untuk megadopsi e-commerce, diantaranya, organizational characteristik, environmental characteristik, leadership characteristik. Untuk menguji manfaat dan kemudahan dalam menggunakan e-commerce dapat menggunakan teori Technology Acceptance Model (TAM).
\end{abstract}

Kata Kunci: e-commerce, karakteristik organsiasi, pengaruh eksternal, kepemimpina, Technology Acceptance Model

\section{A. PENDAHULUAN}

Laju perkembangan Teknologi Informasi (TI) tidak dapat dipungkiri lagi. Bidang bisnis, sosial, perkembangan TI memberikan manfaat yang begitu besar dan masyarakat lebih mudah dalam melakukan transaksi bisnis dan berkomunikasi. Teknologi Informasi (TI) berperan dalam peningkatan mutu perekonomian masyarakat. Laju TI memberi peluang pembangunan di sektor perekonomian dan meningkatkan 
interaksi sosial kearah yang lebih maju melalui teknologi yang ditawarkan serta memberikan kesempatan kepada semua pihak untuk bisa saling berbagi informasi dan pengetahuan(Melhem et al., 2009).

Kementerian Koperasi dan UMKM dikutip dari https://kominfo.go.id/melansir adanya pertumbuhan sejumlah pengusaha yang awalnya $1,6 \%$ menjadi $3,1 \%$ dari populasi yang ada berdasarkan olahandata BPS. Terciptanya lapangan perkerjaan dan laju perekonomian di dukung oleh populasi dari wirausaha sebab mereka dapat melihat peluang dan menciptakan bisnis baru. Terlebih zaman sekarang ini, dalam memulai bisnis nyaris tidak ditemukan kendala.

Namun terjadi perbedaan dengan masa sekarang ini. Organisasi Perburuhan Internasional (ILO) melakukan survei mengenai dampak pandemi Covid-19 terhadap 571 Usaha Mikro Kecil dan Menengah (UMKM). Survei dilakukan pada 6-24 April 2020, dimana hasilnya 70\% UMKM mengalami pemberhentian produksi akibat Covid19 (https://katadata.co.id/berita). Di sisi lain, Menteri Koperasi dan UMKM mengemukakan bahwa pandemi Covid-19 memberikan dampak besar terhadap keberlangsungan UMKM (https://bisnis.tempo.co/read). Lebih lanjut diungkapkan bahwa, pelaku UMKM terkendala dari sisi kesehatan arus kas yang mengharuskan untuk merumahkan tenaga kerja, terkendala pada supply dan kurangnya pembelian dari konsumen. Dari permasalahan tersebutlah dibutuhkan dukungan untuk meningkatkan penjualan dan aliran masuk kas.

Munculnya pasar e-commerce telah menciptakan peluang pasar yang luas bagi para pengecer dan penyedia layanan logistik, dapat meningkatkan kepuasan pembelian dan penjualan serta dapat memfasilitasi kemampuan penyedia layanan logistik untuk mengelolah yang lebih besar (Leung et al., 2020). Meskipun pandemi Covid-19 sedang melanda, namum akses internet tetap bisa di manfaatkan. Dunia e-commerce terbuka lebar untuk pelaku UMKM untuk meningkatkan penjualannya. UMKM secara tidak langsung di paksa untuk mengubah cara transaksi mereka, yang awalnya secara offline maka di masa pandemi ini beralih menjadi online. E-commerce dipercaya dapat meningkatkan penjualan para pelaku UMKM 


\section{B. TINJAUAN PUSTAKA}

\section{E-commerce}

Perdagangan elektronik atau kata lain e-commerce melakukan kegiatan yang berhubungan dengan jual beli dengan memanfaatkan fasilitas internet. Juga melakukan aktivitas yang berkaitan dengan transfer dana, pemasaran jasa ataupun barang. Melalui kegiatan e-commerce, perusahaan memiliki peluang untuk mendapatkan konsumen sebanyak-banyaknya.

E-commercesalah satu fenomena yang sedang terjadi dalam perkembangan kemajuan teknologi. E-commerce telah menggeser aspek kehidupan sehari-hari dan juga menarik minat banyak peneliti dalam mempelajari berbagai aspek yang terkait dengan adopsi penggunaan belanja online. Penelitian sistem informasi telah menjelajahi perilaku konsumen dalam hal berbelanja online (Bhattacherjee, 2001; Gefen et al., 2003; Gefen \& Straub, 2000; Koch et al., 2011; Koufaris, 2002)

Suyanto (2003) menjelaskan beberapa tipe dari e-commerce:

1. Business to business (B2B). Proses transaksi dan interaksi antar perusahaan

2. Business to consumer (B2C). Pelaku bisnis yang terlibat langsung dengan pihak penjual dengan pembeli.

3. Consumer to consumer $(C 2 C)$. Interaksi langsung antara pihak penjual selaku pemegang usaha dengan individu sebagai pembeli

4. Consumer to business $(C 2 B)$. Seorang pelaku bisnis melakukan transaksi dengan perusahaan lainnya.

Memiliki peluang, e-commerce mendapatkan keuntungan yang besar dibandingkan dengan melakukan transaksi secara tradisional, menawarkan pengurangan biaya transaksi dan memberikan kenyamanan bagi seluruh konsumen (Argilés et al., 2020; P. et al., 2020). Dimasa pandemi Covid-19, e-commerce mampu membuat percepatan perkembangan bisnis dan mempercepat penyesuaian operasional (J. Lin et al., 2020).

\section{HASIL DAN PEMBAHASAN}

\section{Technology Acceptance Model (TAM)}

Dalam menjelaskan penerimaan seseorang dalam menggunakan sistem teknologi informasi dapat digunakan model Technology Acceptance Model (TAM).Fred Davis memperkenalkan teori ini, dimana dengan model TAM dapat menganalisis faktor 
apa saja yang dapat memberikan dampak diterimanya suatu sistem. Teori TAM menjelaskan bahwa seseorang ingin menggunakan sistem tersebut dapat ditentukan berdasarkan kemudahan pengguna (perceived ease of use) dan manfaat yang dirasakan (perceived usefulnes). Sistem tersebut akan digunakan jika memiliki manfaat positif bagi penggunanya (Thompson et al., 1991)

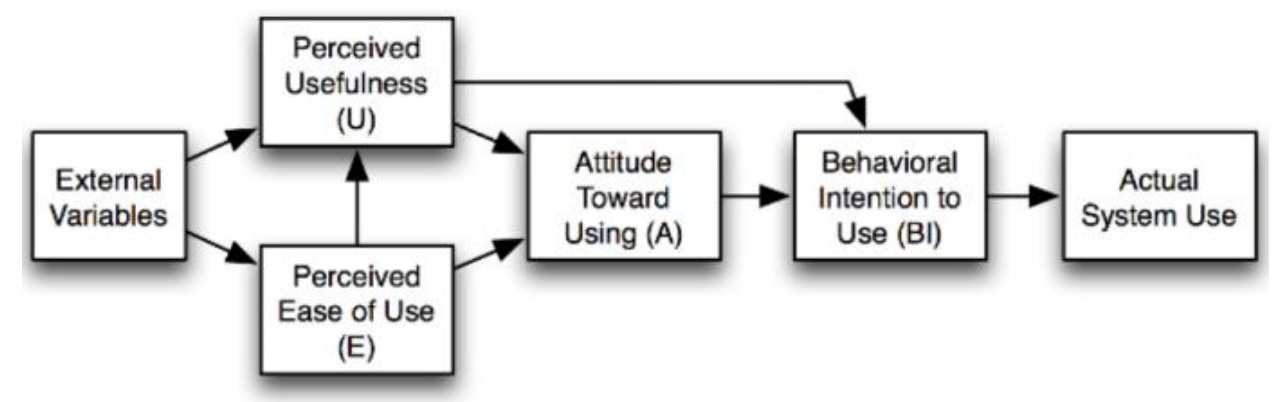

Gambar 1. Technology Acceptance Model (TAM)

Davis et. al, (1989), menjelaskan 5 kontruk TAM:

a) Perceived ease of use, seseorang percaya bahwa dengan menggunakan teknologi dapat memudahkan dan lebih efektif dan efisien dalam pemanfaatan waktu ataupun tenaga.

b) Perceived usefulness, diyakini dengan pemanfaatan teknologi dapat menigkatkan kinerja.

c) Attitude toward using, sikap dalam bentuk penerimaan atau penolakan seseorang dalam menggunakan teknologi.

d) Behavioral intention to use, keinginan dalam menggunakan teknologi.

e) Actual technology usage, tindakan nyata seseorang dalam menggunakan teknologi.

Park et al., (2019) melakukan penelitian pada adopsi teknologi multimedia pembelajaran dengan menggunakan TAM dan menyimpulkan bahwa teknologi multimedia sangat cocok digunakan dalam pembelajaran. Telah dilakukan penelitian pada beberapa faktor yang berpengaruh terhadap penerimaan teknologi baik teknologi multimedia, sistem operasi Xamin yang diperuntukkan untuk UKM di Iran, penerimaan ERP, e-government, service bundles, mobile library diantarannya perceived ease of use, perceived usefulness, attitude, intention dan actual system use(Hong \& Sternthal, 2010; 
Park et al., 2019; Rafique et al., 2020; Saghafi et al., 2017; Schilke \& Wirtz, 2012; Shyu \& Huang, 2011).

\section{Organizational Characteristik}

Tornatzky dan Fleischer (1990)mengembangkan kerangka konseptual TEO yang menyajikan dimensi konteks organisasi yang mempengaruhi adopsi organisasi dan inovasi baru. Fokus utamnya adalah bagaimana teknologi yang ada dalam organisasi serta inovasi yang tersedia di luar organisasi mempengaruhi proses adopsi inovasi. Arpaci et all (2012) mengasumsikan kerangka kerja TOE bahwa proses adopsi dalam organisasi secara efektif ditetapkan oleh faktor internal dan eksternal organisasi.

Untuk membuktikan kekuatan teoritis dan empiris kerangka kerja TOE, telah dilakukan analisis dalam berbagai konteks yang berbeda. Kuan \& Chau, (2001) mengkonfirmasi untuk menyelidiki adopsi inovasi sistem informasi yang kompleks, mereka menggunakan kerangka TOE. Lian et al., (2014) menggunakan kerangka TOE untuk melihat faktor-faktor apa yang mempengaruhi keputusan pihak rumah sakit untuk mengadopsi komputer di rumah sakit. Peran kerangka TOE juga di konfirmasi ketika menganalisis teknologi informasi dan komunikasi (Srivastava \& Teo, 2010).

Ukuran organisasi merupakan faktor utama yang mempengaruhi adopsi teknologi (Elbanna \& Child, 2007; Jeyaraj et al., 2006; Kankanhalli et al., 2003; Sabherwal et al., 2006). Permintaan penggunaan teknologi informasi di pengaruhi oleh ruang lingkup yang besar (Dewan \& Kraemer, 2000). Hasil penelitian Salwani et al., (2009) mengemukakan bahwa ruang lingkup organisasi yang besar mengharuskan organisasi tersebut untuk menggunakan teknologi informasi.

Pengenalan sistem informasi yang baru secara fundamental mengubah cara organisasi menyelesaikan masalah yang menghasilkan budaya sistem informasi yang baru. Dalam kebijakan manajemen, budaya organisasi terbukti memiliki peran penting (Cabrera et al., 2008). Budaya organisasi dapat memberikan dampak pada pengembangan dan implementasi baru pada sistem informasi. Furnell \& Thomson, (2009)mengemukakan bahwa budaya penggunaan sistem berpengaruh terhadap adopsi keamanan sistem informasi. 


\section{Environmental Characteristik}

Lingkungan eksternal memberikan peluang (informasi, sumber daya, teknologi) dan kendala (regulasi, pembatasan modal atau informasi). Adopsi inovasi dapat menjadi sarana organisasi untuk memanfaatkan peluang lingkungan eksternal (Damanpour \& Schneider, 2006). Kualitas layanan online adalah hal yang sangat penting faktor yang dapat berkontribusi secara signifikan terhadap kepuasan pelanggan (Loiacono et al., 2002; Zeithmal et al., 2002). Kualitas informasi dapat mempengaruhi pengguna e-commerce terhadap kepuasan pelanggan (Aggelidis \& Chatzoglou, 2009; Moon \& Kim, 2001). Sistem dikatakan berkualitas jika sistem tersebut memberikan manfaat bagi penggunanya (Jeong, 2011). Kualitas sistem informasi berkaitan dengan kemudahan, aksebilitas dan penerimaan sistem informasi (Khan 2 \& Qutab 2, 2016).

Salah satu kategori utama SQB adalah komitmen psikologis yang meliputi biaya tertanam (sunk cost)norma sosial dan upaya untuk memegang kendali. Biaya tertanam (sunk cost) penting terkait dengan resistensi keputusan terhadap penggunaan sistem informasi karena untuk beradaptasi dengan sistem yang baru (Lending \& Straub, 1997). A. Lin \& Chen, (2012) berpendapat bahwa perilaku sunk cost dapat terjadi ketika perusahaan ingin mengadopsi layanan sistem yang baru karena dapat meningkatkan infrastruktur perusahaan.

Biaya transaksi (transaction cost) merupakan manfaat yang di rasakan oleh pengguna dan akan beralih dari sttaus quo ke sistem informasi yagn baru (Kim \& Kankanhalli, 2009). A. Lin \& Chen, (2012) berpendapat bahwa biaya (transaction cost) dapat dijadikan perhatian khusus oleh seorang manajer dalam mempertimbangkan untuk menggunakan teknologi informasi yang baru.

\section{Leadership Characteristik}

Kepemimpinan transformasional menciptakan tantangan dan harapan untuk meningkatkan kinerja yang lebih tinggi. Bass et al., (2003) menggambarkan kepemimpinan transformasional dengan membagi menjadi empat faktor yaitu charisma, inspirational motivation, intellectual stimulation, individualized consideration.

(Elkhani et al., 2014) mengemukakan bahwa transformasional leadership memiliki peran dalam pengambilan keputusan untuk menggukan sistem informasi, sehingga pemimpin harus bisa menginspirasi bawahannya untuk lebih aktif lagi dalam 
menggunakan teknologi yang baru. Aldholay et al., (2018); Carreiro \& Oliveira, (2019) menjelaskan bahwa transformasional leadership sangat terkait dengan adopsi inovasi sistem informasi.

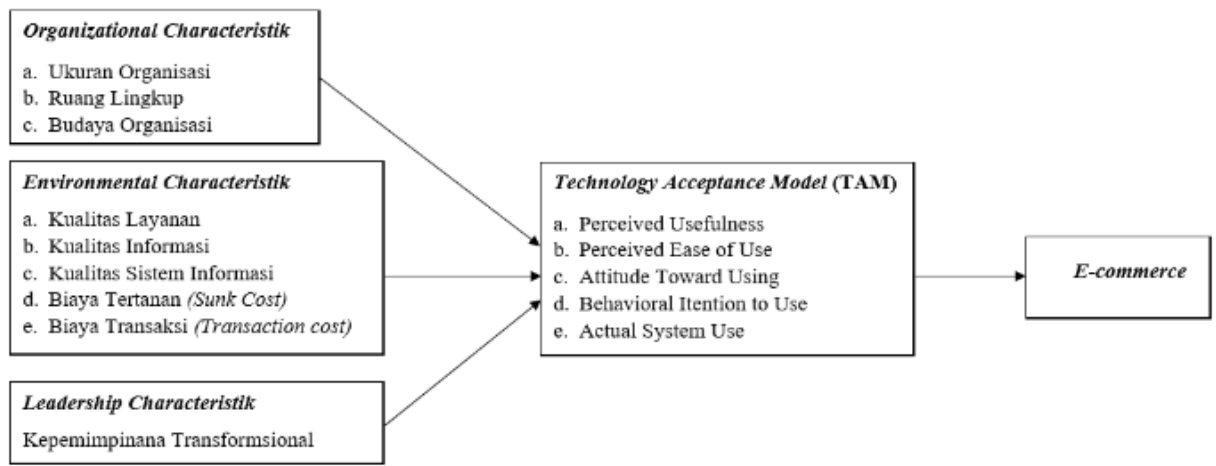

Gambar 2. Model Untuk Adopsi E-Commerce Dalam Mendukung Perkembangan UMKM di Masa Pandemi Covid-19

\section{SIMPULAN}

Era digital memunculkan peluang yang sangat besar khususnya dunia bisnis dalam menciptakan berbagai platform perangkat lunak untuk meningkatkan kinerja bisnisnya. Lahirnya berbagai jenis platform sangat memudahkan para pelaku bisnis dalam memperkenalkan bisnisnya dan bahkan dalam melakukan transaksi.

UMKM dapat bersaing dengan memanfaatkan dan menggunakan teknologi internet. Pengaplikasian internet memberikan dampak dan manfaat yang besar dalam dunia bisnis. Dengan menggunakan e-commerce dapat meningkatkan penjualan barang dan jasa serta dapat bersaing dengan bisnis yang lainnya. Pemanfaatan e-commerce dapat memasarkan secara fisik atau digital dengan bermacam-macam produk dan jasa.

Bukan hal yang mustahil, dimasa pandemi Covid-19 ini pelaku UMKM di paksa untuk mengadopsi e-commerce untuk membangkitkan kembali gairah penjualan dan arus kas. Berbagai penelitian telah dilakukan sebelum adanya pandemi Covid-19 bahwa e-commerce sangat membantu dalam proses jual beli. E-commerce semakin populer dan memberikan dampak yang signifikan terhadap peningkatan hasil penjulan (Lian et al., 2014; J. Lin et al., 2020).

Kerangka konseptual ini menyajikan beberapa faktor yang dapat mempengaruhi dalam mengadopsi e-commerce, diantaranya karakteristik organisasi, pengaruh eksternal, dan kepemimpinan. Kepuasan dan manfaat yang di rasakan dalam 
mengadopsi e-commerce dapat di ukur menggunakan Technology Acceptance Model (TAM). Pelaku UMKM harus bisa memanfaatkan faktor-faktor tersebut dalam mengadopsi penggunaan teknologi khususnya e-commerce.

Untuk budaya organisasi, biaya tertanam (sunk cost), biaya transaksi (transaction cost) dan kepemimpinan transformasional perlu dikaji lebih lanjut lagi dengan kaitannya dalam mengadopsi teknologi informasi. Hal ini dikarenakan masih kurangnya literatur yang membahas hal tersebut.

\section{DAFTAR PUSTAKA}

Aggelidis, V. P., \& Chatzoglou, P. D. (2009). Using a modified technology acceptance model in hospitals. International Journal of Medical Informatics, 78(2), 115-126.

Aldholay, A. H., Isaac, O., Abdullah, Z., \& Ramayah, T. (2018). The role of transformational leadership as a mediating variable in DeLone and McLean information system success model: The context of online learning usage in Yemen. Telematics and Informatics, 35(5), 1421-1437.

Argilés, J., Ravenda, D., \& Garcia-Blandon, J. (2020). E-Commerce and Labour Tax Avoidance. Critical Perspectives on Accounting, xxxx.

Arpaci, I., Yardimci, Y. C., Ozkan, S., \& Turetken, O. (2012). Organizational adoption of information technologies: A literature review. International Journal of eBusiness and eGovernment Studies, 4(2), 37-50.

Bass, B. M., Avolio, B. J., Jung, D. I., \& Berson, Y. (2003). Predicting unit performance by assessing transformational and transactional leadership. Journal of Applied Psychology, 88(2), 207-218.

Bhattacherjee, A. (2001). An empirical analysis of the antecedents of electronic commerce service continuance. Decision Support Systems, 32(2), 201-214.

Cabrera, Á., Cabrera, E. F., \& Barajas, S. (2008). The key role of organizational culture in a multi-system view of technology-driven change. Global Information Systems: The Implications of Culture for IS Management, 21, 178-199.

Carreiro, H., \& Oliveira, T. (2019). Impact of transformational leadership on the diffusion of innovation in firms: Application to mobile cloud computing. Computers in Industry, 107, 104-113.

Damanpour, F., \& Schneider, M. (2006). Phases of the adoption of innovation in organizations: Effects of environment, organization and top managers. British Journal of Management, 17(3), 215-236. 
Davis, F. D. (1989). Perceived Usefulness, Perceived Ease of Use, and User Acceptance of Information Technology. Management Information System Quartely, September: 319- 358 .

Dewan, S., \& Kraemer, K. L. (2000). Information technology and productivity: Evidence from country-level data. Management Science, 46(4), 548-562.

Elbanna, S., \& Child, J. (2007). Influences On Strategic Decision Effectiveness: Development And Test Of An Integrative Model. Business, 28(February), 431453.

Elkhani, N., Soltani, S., \& Ahmad, M. N. (2014). The effects of transformational leadership and ERP system self-efficacy on ERP system usage. Journal of Enterprise Information Management, 27(6), 759-785.

Furnell, S., \& Thomson, K. L. (2009). From culture to disobedience: Recognising the varying user acceptance of IT security. Computer Fraud and Security, 2009(2), 510 .

Gefen, D., Karahanna, E., \& Straub, D. W. (2003). TRUST AND TAM IN ONLINE SHOPPING: AN INTEGRATED MODEL1 By: MIS Quarterly, 27(1), 51-90.

Gefen, D., \& Straub, G. (2000). The Relative Importance of Perceived Ease of Use in IS Adoption: A Study of E-Commerce Adoption. Journal of the Association for Information Systems, 1(1), 1-30.

Hong, J., \& Sternthal, B. (2010). The effects of consumer prior knowledge and processing strategies on judgments. Journal of Marketing Research, 47(2), 301311.

https://katadata.co.id

https://kominfo.go.id/

https://bisnis.tempo.co

Jeong, H. (2011). An investigation of user perceptions and behavioral intentions towards the e-library. Library Collections, Acquisitions, \& Technical Services, $35(2-3), 45-60$.

Jeyaraj, A., Rottman, J. W., \& Lacity, M. C. (2006). A review of the predictors, linkages, and biases in IT innovation adoption research. Journal of Information Technology, 21(1), 1-23.

Kankanhalli, A., Teo, H. H., Tan, B. C. Y., \& Wei, K. K. (2003). An integrative study of information systems security effectiveness. International Journal of Information Management, 23(2), 139-154.

Khan 2, A., \& Qutab 2, S. (2016). Understanding research students' behavioural intention in the adoption of digital libraries. Library Review, 65(4/5), 295-319. 
Kim, H.-W., \& Kankanhalli, A. (2009). Investigating User Resistance Implementation: A Status Quo Bias Systems Introduction. MIS Quarterly, 33(3), 567-582.

Koch, S., Toker, A., \& Brulez, P. (2011). Extending the Technology Acceptance Model with perceived community characteristics. Information Research, 16(2).

Koufaris, M. (2002). Applying the Technology Acceptance Model and Flow Theory to Cyworld User Behavior. Information Systems Research, 13(2), 205-223.

Kuan, K. K. Y., \& Chau, P. Y. K. (2001). A perception-based model for EDI adoption in small businesses using a technology-organization-environment framework. Information and Management, 38(8), 507-521.

Lending, D., \& Straub, D. W. (1997). Impacts of an integrated information center on faculty end-users: A qualitative assessment. Journal of the American Society for Information Science, 48(5), 466-471.

Leung, K. H., Lee, C. K. M., \& Choy, K. L. (2020). An integrated online pick-to-sort order batching approach for managing frequent arrivals of B2B e-commerce orders under both fixed and variable time-window batching. Advanced Engineering Informatics, 45(February), 101125.

Lian, J. W., Yen, D. C., \& Wang, Y. T. (2014). An exploratory study to understand the critical factors affecting the decision to adopt cloud computing in Taiwan hospital. International Journal of Information Management, 34(1), 28-36.

Lin, A., \& Chen, N. C. (2012). Cloud computing as an innovation: Percepetion, attitude, and adoption. International Journal of Information Management, 32(6), 533-540.

Lin, J., Li, L., Luo, X. R., \& Benitez, J. (2020). How do agribusinesses thrive through complexity? The pivotal role of e-commerce capability and business agility. Decision Support Systems, March, 113342.

Loiacono, E. T., Watson, R. T., \& Goodhue, D. L. (2002). WebQual: A measure of website quality. In AMA Winter Conference, 1-12.

Melhem, S., Morell, C., \& Tandon, N. (2009). Information and Communication Technologies for Women's Socio-Economic Empowerment. In World Bank Working Paper No. 17.

Moon, J. W., \& Kim, Y. G. (2001). Extending the TAM for a World-Wide-Web context. Information and Management, 38(4), 217-230.

P., D., Babu, S. S., \& Vijayalakshmi, Y. (2020). Enhancement of e-commerce security through asymmetric key algorithm. Computer Communications, 153, 125-134. 
Park, C. W., Kim, D. gook, Cho, S., \& Han, H. J. (2019). Adoption of multimedia technology for learning and gender difference. Computers in Human Behavior, 92, 288-296.

Rafique, H., Almagrabi, A. O., Shamim, A., Anwar, F., \& Bashir, A. K. (2020). Investigating the Acceptance of Mobile Library Applications with an Extended Technology Acceptance Model (TAM). Computers and Education, 145, 103732.

Sabherwal, R., Jeyaraj, A., \& Chowa, C. (2006). Information system success: Individual and organizational determinants. Management Science, 52(12), 1849-1864.

Saghafi, F., Noorzad Moghaddam, E., \& Aslani, A. (2017). Examining effective factors in initial acceptance of high-tech localized technologies: Xamin, Iranian localized operating system. Technological Forecasting and Social Change, 122, 275-288.

Salwani, M. I., Marthandan, G., Norzaidi, M. D., \& Chong, S. C. (2009). E-commerce usage and business performance in the Malaysian tourism sector: Empirical analysis. Information Management and Computer Security, 17(2), 166-185.

Schilke, O., \& Wirtz, B. W. (2012). Consumer acceptance of service bundles: An empirical investigation in the context of broadband triple play. Information and Management, 49(2), 81-88.

Shyu, S. H. P., \& Huang, J. H. (2011). Elucidating usage of e-government learning: A perspective of the extended technology acceptance model. Government Information Quarterly, 28(4), 491-502.

Srivastava, S. C., \& Teo, T. S. H. (2010). E-government, e-business, and national economic performance. Communications of the Association for Information Systems, 26(1), 267-286.

Suyanto,M (2003) Strategi Periklanan pada E Commerce Perusahaan Top Dunia, Penerbit Andi, Yogyakarta

Thompson, R. L., Higgins, C. A., dan Howel, J. M. (1991). Personal Computing: Toward a Conceptual Model of Utilization. Management Information System Quartely, 15, 125- 143

Tornatzky, L. G., \& Fleischer, M. (1990). The processes of technological innovation. Lexington, MA: Lexington Books.

Zeithmal, V.A., Parasuraman, A. and A., M. (2002). An Empirical Examination of the Service Quality - Value-Locality Chain in an Electronic Channel, Working. Paper, University of North Carolina, Chapel Hill, NC. 
65 | C A P I T A L, V O L UME 4, NOMOR 1, SEPTEMBER 2020 